\section{Problematic internet use among students of mental health: Preliminary findings from eastern India}

Sir,

Originally designed for a small group of researchers and academicians; Internet has now become an integral part of the daily life the common man. Use of Internet has increased dramatically over past several years. In 2010, the world's Internet users constituted $28.7 \%$ of the population, having grown by $444.8 \%$ over the preceding decade. India's current Internet user base is about 243 million strong ( $9.5 \%$ of global Internet users) and may touch 370 million by 2015 , thus clocking the highest incremental growth in the world. ${ }^{[1]}$

Despite tremendous benefits of the internet; a proportion of users experience negative consequences of excessive Internet use and develop symptoms that mimic substance-addiction. ${ }^{[2,3]}$ With a ubiquitous penetration of internet in every sphere of life, medical students might become particularly vulnerable to these ill-effects. Long hours spent on the Internet to update themselves on latest in research and medical education, along with boredom arising out of living away from their homes and families, might make them prone to become internet addicts and might prove disastrous for their profession. In case of students of mental health, the scenario is further complicated by the fact that they are the ones who are presumed to be well aware of the ill effects of addiction and have knowledge on prevention and management of such "temptations." Given the two contrasting forces of wisdom at work, the present report aims at estimating the 
prevalence and pattern of problematic Internet use (PIU) in mental health students.

As part of a larger study, 126 doctors and students undergoing training at tertiary psychiatry facilities in eastern India were initially screened, and 80 were selected for inclusion. Those with psychiatric co-morbidities, substance dependence, and those unwilling to participate were excluded. 41 of the subjects were postgraduate students of psychiatry (medical doctors) and the rest were enrolled in M.Phil. courses in Clinical Psychology/ Psychiatric social work.

Sociodemographic data was collected. Young's internet addiction test (IAT) ${ }^{[4]}$ was used to assess internet use pattern. The data were analyzed using SPSS v. 20 (IBM-SPSS Corporation, New York). Frequency counts of categorical variables and mean/ standard deviation of continuous variables were calculated. A cut-off of 49 on IAT was used to identify cases with PIU. Subjects with and without PIU were compared using Chi-square/Fisher exact test or $t$-tests (as applicable).

There were 34 males and 46 female subjects. The average age of the sample was $26.48 \pm 2.64$ years. 68 were Hindus, 6 practiced Islam, 3 followed Christianity, and 3 did not wish to disclose their faith. 61 of the subjects were staying away from family members, and 68 were unmarried. Of the 12 married respondents, 4 had children. 56 were from nuclear families, 19 from joint families, and 5 from extended ones. Two reported a positive family history of psychiatric disorder (both of the affective nature). 55 had access to free-Internet through Wi-Fi, while 25 did not. Mean score on IAT in the sample was $28.60 \pm 18.28$. Mean score was $24.20 \pm 16.86$ among females, and $35.26 \pm 18.44$ among males $(P=0.007) .12$ of the 80 respondents $(15 \%)$ had IAT score above 49 , indicating PIU. ${ }^{[4]}$ There was nil significant $(P>0.05)$ difference between those with and without PIU in terms of gender, family structure, living away or access to free internet.

In terms of websites visited, social-networking sites ranked number $1(46.25 \%)$ followed by scholarly sites $(21.25 \%)$ and search engines $(17.50 \%)$. Though the visit to adult sites was not assessed specifically; 11 reported visiting them "once-in-a-while," all of whom were males. In those with PIU, $91.66 \%$ of the respondents reported social networking sites as their most favored ones compared to $38.24 \%$ of those without $(P=0.016)$. Those with PIU also spent more time online $(>90 \%$ reported $>4 \mathrm{~h} /$ day; $P=0.001)$.

We report a $15 \%$ prevalence of PIU in this group; in broad agreement with literature, which reports from $1 \%$ in $^{[5]}$ to $36.7 \%{ }^{[6]}$ prevalence of PIU/IA among youths, with most estimates hovering around $10 \%$-mark. ${ }^{77,8]}$ We also found that those with PIU have a significantly greater propensity to use social-networking sites and stay online for a longer duration, compared to those without. Scherer, in $1997,{ }^{[9]}$ had reported that dependent users were predisposed to spend at least twice as much time online for leisure activities compared to nondependent's. Morahan-Martin and Schumacher ${ }^{[10]}$ found that pathological Internet users are more likely to use Internet for meeting new people, using adult-only resources, relaxing, socializing, and playing highly interactive online games. Kubey et al. found in $2001^{[11]}$ that self-reported Internet dependency and impaired academic performance were associated with the use of Internet applications such as chat rooms and multiple user dungeons. As these studies were conducted in presocial-network era; we argue that the current proliferation of, and ease of access to, social networking sites have replaced these earlier websites while providing the users with similar reinforcements.

Among non-PIU users, we report a significantly higher score in males compared to females. Joiner et al..$^{12]}$ had found that overall males' total use of the internet $(16.02 \mathrm{~h})$ was higher than females' $(14.08 \mathrm{~h})$; and a more recent report by Malviya et al., ${ }^{[13]}$ males represent double the number of females, among 242 medical undergraduates in India, in having IA. Literature further suggests a male-preference for power, control, passion, and pornography on internet, ${ }^{[14]}$ in contrast to female indulgence in use of technology for accomplishing a task. ${ }^{[15]}$ Therefore, our finding indicates that males might be more predisposed to develop PIU under similar circumstances, perhaps because of a fundamental difference in the way the use Internet.

This report is a preliminary attempt at characterizing PIU among young mental health professionals in India. This is an important study group, both because of an increased "need for exposure" to the Internet as well as because of a "professional awareness" about the ill effects of behavioral addictions. The findings are of significance, and warrants further research in this regard in order to establish the psycho-social correlates of PIU in this group. 
Sayantanava Mitra, Tathagata Mahintamani, Vipin Kumar, Shuvabrata Poddar², Urbi Mukherjee', Anjana Rao Kavoor ${ }^{4}$, Seshadri Sekhar Chatterjee ${ }^{5}$

Department of Psychiatry, Sarojini Naidu Medical College, ${ }^{4}$ Department of Psychiatry, Institute of Mental Health and Hospital,

Agra, Uttar Pradesh, Departments of ${ }^{1} P$ sychiatry and ${ }^{2}$ Clinical Psychology, Central Institute of Psychiatry, Ranchi, Jharkhand,

${ }^{3}$ Department of Applied Psychology, University of Calcutta, ${ }^{5}$ Department of Psychiatry, Medical College, Kolkata, West Bengal, India

Address for correspondence: Dr. Shuvabrata Poddar, Department of Clinical Psychology, Central Institute of Psychiatry, Ranchi, Jharkhand, India. E-mail: sayantanava@gmail.com

\section{References}

1. Manual for Measuring ICT Access and Use by Households and Individuals, 2014. International Telecommunication Union (ITU); (Internet World Stats, 2014). www.itu.int/dms_pub/itu-d/opb/.../DIND-ITCMEAS-2014-PDF-E.pdf. [Last accessed on 2014 May 10].

2. Young K. Internet addiction: The emergence of a new clinical disorder. Cyberpsychol Behav 1996;1:237-44.

3. Mythily S, Qiu S, Winslow M. Prevalence and correlates of excessive Internet use among youth in Singapore. Ann Acad Med Singapore 2008;37:9-14

4. Young KS. Internet Addiction Test. Available from: http://www. netaddiction.com/resources/internet_addiction_test.htm. [Last accessed on 2014 Jul 25].

5. Tsitsika A, Critselis E, Kormas G, Filippopoulou A, Tounissidou D, Freskou A, et al. Internet use and misuse: A multivariate regression analysis of the predictive factors of internet use among Greek adolescents. Eur J Pediatr 2009;168:655-65.

6. Milani L, Osualdella D, Di Blasio P. Quality of interpersonal relationships and problematic Internet use in adolescence. Cyberpsychol Behav 2009;12:681-4.

7. Kim K, Ryu E, Chon MY, Yeun EJ, Choi SY, Seo JS, et al. Internet addiction in Korean adolescents and its relation to depression and suicidal ideation: A questionnaire survey. Int J Nurs Stud 2006;43:185-92

8. Thomas NJ, Martin FH. Video-arcade game, computer game and Internet activities of Australian students: Participation habits and prevalence of addiction. Aust J Psychol 2010;62:59-66.

9. Scherer K. College life on-line: Healthy and unhealthy Internet use. J Coll Stud Dev 1997;38:655-65.

10. Morahan-Martin J, Schumacher P. Incidence and correlates of pathological Internet use among college students. Comput Human Behav 2000;16:13-29.

11. Kubey RW, Lavin MJ, Barrows JR. Internet use and collegiate academic performance decrements: Early findings. J Commun 2001;51:366-82.

12. Joiner R, Gavin J, Duffield J, Brosnan M, Crook C, Durndell A. et al. Gender, Internet identification, and Internet anxiety: Correlates of Internet use. Cyberpsychol Behav 2005;8:371-78.

13. Malviya A, Dixit $\mathrm{S}$, Shukla $\mathrm{H}$, et al.A Study to evaluate Internet addiction disorder among students of a medical college and associated hospital of central India. Natl J Community Med 2014;5:93-5.

14. Young KS. Internet addiction: The emergence of a new clinical disorder. Cyberpsychol Behav 1998;1:237-44.

15. Tsai CC, Lin SS. Internet addiction of adolescents in Taiwan: An interview study. Cyberpsychol Behav 2003;6:649-52.

\begin{tabular}{|l|l|}
\hline \multicolumn{2}{|c|}{ Access this article online } \\
\hline Quick Response Code: & Website: \\
\hline & www.ruralneuropractice.com \\
\cline { 2 - 2 } & \\
\hline & \\
\hline
\end{tabular}

